\title{
Caracterización y Marcación de Células Germinales Primordiales
}

\author{
Characterization and Marking of Primordial Germ Cells
}

\author{
A. Stevenson*; M. Obaíd"; R. Romina* \& L. Vigneaux**
}

STEVENSON, A.; OBAÍD, M.; ROMINA, R. \& VIGNEAUX, L. Caracterización y marcación de células germinales primordiales. Int. J. Morphol., 34(2):628-636, 2016.

RESUMEN: Las células germinales primordiales (CGP) son los precursores de los ovocitos y espermatocitos. Se caracterizan por ser las únicas capaces de retener verdaderamente la capacidad de desarrollo pluripotencial luego de la gastrulación. Estas células provienen del epiblasto, diferenciándose del resto de las células somáticas gracias a señales emitidas por el ectodermo extraembrionario y endodermo visceral tempranamente a partir de los días 6,0 a 7,5 dpc. en la especie murina. Luego migran a través de intestino primitivo y mesenterio dorsal hasta llegar a las crestas genitales alrededor de los 10,5 dpc. Las células germinales primordiales tienen una variada morfología y expresión génica, por lo tanto presentan distintos marcadores según el estadío en el que se encuentren. Dentro de los marcadores más estudiados y caracterizados se encuentran fragillis, c-Kit, Stella, DAZ, Vasa, GCNA1, Blimp1 y SSEA-1.

PALABRAS CLAVE: Células germinales primordiales; Marcadores; Pluripotencial.

\section{INTRODUCCIÓN}

Las células germinales primordiales (CGP) son los precursores de los ovocitos y espermatocitos, células encargadas de la mantención del genoma en la especie. La línea germinal puede detectarse desde los primeros días del embrión. En la especie murina, el cual es uno de los modelos más estudiados, a los $8 \mathrm{dpc}$ (días post-coito) se pueden observar un grupo de células en el extremo anterior de la línea primitiva positivas para el marcador de fosfatasas alcalinas no tejido-específica (TNAP) (McLaren, 2003). Estas células provienen del epiblasto, diferenciándose del resto de las células somáticas a través de señales emitidas por el ectodermo extraembrionario y endodermo visceral como el BMP4, BMP8 y BMP2. Gracias a esta estimulación las CGP liberan la proteína Blimp1, que reprime genes mesodérmicos y expresa genes asociados a la pluripotencialidad (DeSousa Lopes et al., 2007). Luego a partir de los 8,5 dpc, éstas células TNAP (+) proliferan y comienzan a migrar. Primero se ubican en el área del endodermo que dará origen a la base del alantoides. A los $10 \mathrm{dpc}$ migran a través de intestino primitivo y mesenterio dorsal hasta llegar a las crestas genitales. Las CGP completan la migración hacia las crestas genitales a los 11,0 dpc aproximadamente, lugar donde entran en meiosis si el embrión es hembra, o mitosis en el caso del macho
(McLaren).

El objetivo de este trabajo es realizar una revisión sobre las CGP y sus marcadores, características en cuanto a pluripotencialidad, técnicas de estudio y mecanismos de desarrollo.

\section{Marcadores de Células Germinales Primordiales.}

Clásicamente las CGP en el embrión son marcadas con TNAP, sin embargo este marcador no es específico para estas células ya que también es expresado por las células somáticas que las rodean (Saiti \& Lacham-Kaplan, 2007). Su expresión en las CGP de ratón se puede observar desde los 7,25 dpc. Sin ser necesario para la sobrevida de estas células, su expresión se mantiene desde la base del alantoides o futuro alantoides hasta la entrada a la cresta genital (McLaren).

Existen una serie de genes y proteínas que se asocian a distintas etapas durante el desarrollo, migración y diferenciación de las CGP. Es así como se describen distintos marcadores que permiten identificar y distinguir a estas células. Es difícil encontrar un marcador específico para las CGP, ya que muchos de los genes expresados por

\footnotetext{
* Magister en Ciencias Médicas y Biológicas Mención Morfología. Laboratorio de Embriología Comparada, Programa de Anatomía y Biología del Desarrollo, ICBM. Facultad de Medicina, Universidad de Chile, Santiago, Chile.

** Laboratorio de Embriología Comparada, Programa de Anatomía y Biología del Desarrollo, ICBM. Facultad de Medicina, Universidad de Chile, Santiago, Chile.
} 
estas, también lo son por las células que las rodean, y algunos participan en la mantención y regulación de su pluripotencialidad (Saiti \& Lacham-Kaplan). A continuación se describen los principales marcadores de las CGP.

Fragilis, es un miembro de la familia de genes de proteínas transmembrana inducidas por interferón (Saitou et al., 2002; Tanaka \& Matsui, 2002). Dentro de esta familia existen cinco proteínas compuestas por 104 a 144 aminoácidos y formadas por dos dominios transmembrana. De estos genes y proteínas, sólo fragilis 1 (Mil-1 o Ifitm-3), fragilis 2 (Mil-2 o Ifitm-1) y fragilis 3 (Mil-3 o Ifitm-2) se encuentran relacionados con las CGP (Lange et al., 2003). Respecto a estos, la expresión de fragilis 1 es detectada desde los 6,25 dpc (ratón) en la región más proximal del epiblasto. Luego de los 6,5 dpc, su expresión cambia al extremo posterior del embrión en donde está restringida a un grupo celular dentro del mesodermo extraembrionario. Después de los 7,25 dpc su expresión predomina a nivel de las CGP (Saitou et al. 2003). Al contrario de fragilis 1 que se va restringiendo en su expresión durante la gastrulación, fragilis 2 y 3 mantienen su expresión en el epiblasto, mesodermo y precursores de CGP (Lange et al.). Tanto fragilis 1 como fragilis 2 son expresados en las CGP durante su migración hacia la cresta genital a los 9,5 dpc y luego en la gónada fetal a los 13,5 dpc (Tanaka \& Matsui).

El marcador c-Kit corresponde a un receptor de proteína transmembrana tipo tirosina quinasa asociado a la maduración de las células germinales (Sette et al., 2000). Sobre este actúa el ligando stem cell factor (SCF), también conocido como factor Steel. In vitro, este sistema c-kit/SCF previene la apoptosis y estimula la proliferación de las CGP. Este complejo c-kit/SCF además participa en el proceso de migración de las CGP (Farini et al., 2007). La expresión de c-kit en las CGP comienza desde los 7,5 dpc hasta los 13,5 dpc posterior a la llegada a las crestas genitales (Saiti \& Lacham-Kaplan). El marcador c-Kit es expresado en las CGP durante su migración hacia la cresta genital, mientras que las células somáticas a lo largo de este trayecto expresan SCF (Sette et al.). La expresión de c-Kit reaparece en las espermatogonias diferenciadas y los espermatocitos, para luego desaparecer en su paso hacia espermátidas. Su expresión es heterogénea en el sentido de que varía según el período de desarrollo de las CGP, pero además también en la presencia simultánea de CGP positivas como negativas para c-Kit. Esta simultaneidad de las CGP se observa a los 10,5 dpc mediante análisis FACS. Posteriormente existe una tendencia a la elevación de este marcador hacia los 12,5 dpc en las CGP, pero no en la totalidad de éstas. Esta heterogeneidad podría ser causa de un mecanismo celular intrínseco o de las células somáticas y/o matriz extracelular en relación a las CGP (Morita-Fujimura et al., 2009)
Stella es un gen que codifica para una proteína que se encuentra tanto a nivel del núcleo como del citoplasma celular en embriones pre-implantacionales (Saitou et al., 2002). La expresión de este marcador persiste hasta la etapa de blastocisto luego de la cual desaparece hasta los $7 \mathrm{dpc}$ momento en el que vuelve a expresarse (Sato et al.; Saitou et al., 2002). Stella aparentemente no es necesario para el desarrollo de la línea germinal (Payer et al., 2003). En el trabajo de Payer et al., no encontraron grandes anormalidades en el desarrollo de célula germinal en stella -/. Una posible explicación, sería por una redundancia funcional compensatoria de los genes relacionado con stella. Continúa siendo positivo en las CGP durante su migración hacia el mesenterio dorsal a los $8,5 \mathrm{dpc}$, manteniendo su expresión hasta los 13,5 dpc en el sexo femenino y hasta los 15,5 dpc en el sexo masculino (Sato et al.). La expresión se reanuda dentro de los ovocitos inmaduros de los ovarios de los recién nacidos, y se sigue expresando en los ovocitos en maduración, sin embargo no se detecta expresión de Stella en los testículos adultos (Saiti \& Lacham-Kaplan).

La familia de genes DAZ está compuesta por 3 miembros; BOULE, DAZL (Deleted in Azoospermia-Like) y DAZ (Yen, 2004). En base a fenotipos de ratones mutantes nulos para DAZL y sus patrones de expresión asociados, se concluye que posee una función tanto en el desarrollo de las CGP como en su diferenciación y maduración (Yen, 2004). La expresión de DAZL comienza en ratones a los $11,5 \mathrm{dpc}$ en las CGP post-migratorias (Saiti \& Lacham-Kaplan).

Vasa corresponde a una helicasa de ARN ATP-dependiente perteneciente a la familia DEAD box y que actúa como regulador transcripcional de ARNm. Mutaciones de la región codificante del gen Vasa producen esterilidad del sexo femenino que incluye defectos de la ovogénesis, diferenciación anormal de la línea celular germinal y de la determinación de los ovocitos. Específicamente en ratón, se denomina Mvh (mouse vasa homologue). Su expresión no ha sido detectada en ningún tejido o célula embrionaria, pareciendo ser exclusivo de las CGP (Toyooka et al., 2000). Se describe la expresión de este marcador en una etapa postmigratoria, a nivel de la cresta genital, entre los 10,5-12,5 dpc (Saiti \& Lacham-Kaplan). Su expresión en el sexo femenino decrece con la maduración del ovocito hasta desaparecer, mientras que en el sexo masculino se asocia a la aparición de cuerpos cromatoídeos (complejos gránulos fibrilares perinucleares) en espermatocitos y espermátidas (Toyooka et al.).

GCNA1 (Germ cell nuclear antigen 1) corresponde a un antígeno expresado a nivel nuclear en las células germinales, tanto del sexo masculino como femenino. Su expresión por parte de las CGP se inicia entre los 10,5 a 
$11,5 \mathrm{dpc}$, una vez que estas células ya han llegado a la cresta genital (Enders \& May, 1994). En el sexo femenino su expresión se mantiene hasta el día 14 post-parto mientras que en el masculino hasta las espermatogonias, espermatocitos en leptoteno y zigoteno y hasta en las espermátidas, luego de lo cual ya no se pesquisa (Enders \& May).

Blimp1 (B-lymphocyteinduced maturation protein1) también conocido como Prdm1, funciona mediante la formación de un complejo con Prmt5 (arginine metiltransferase). Las células positivas para Blimp1 en etapas tempranas del desarrollo, contribuyen a las CGP positivas para Stella, lo que se correlaciona con una inducción en el epiblasto proximal hacia un linaje restringido de precursores de CGP (Kurimoto et al., 2008). Su expresión comienza a través de todo el hipoblasto en etapas tempranas para luego ser expresada solo en precursores de CGP en el epiblasto posterior y posteriormente en algunas células mesodérmicas (Hopf et al., 2011). Su expresión se inicia a los 6,25 dpc en el epiblasto proximal-posterior justo en momentos previos al inicio de la gastrulación, y se mantiene durante la migración de las CGP hacia las crestas genitales (Ohinata et al., 2005). La expresión de este marcador tendría un rol sobre la especificación inicial de las CGP más que en relación a la proliferación y sobrevida de éstas (Saiti \& Lacham-Kaplan). Blimp1 es esencial para reprimir casi todos los genes normalmente regulados río abajo en las CGP en relación a sus células somáticas vecinas y así mediar la vía de inhibición de la diferenciación somática. En contraste, no es necesario para la activación de aproximadamente la mitad de los genes regulados río arriba en las CGP, revelando mecanismos independientes de Blimp1 para la especificación de las CGP (Kurimoto et al.).

SSEA-1, SSEA-3 y SSEA-4 corresponden a antígenos embrionarios etapa específicos que se unen a moléculas tipo glicoproteínas presentes en la superficie de las CGP. El más utilizado como marcador en CGP es el SSEA-1, el cual es un trisacárido encontrado en las células de carcinoma embrionario de ratón y en células embrionarmias en etapa de 8 células (Soto-Suazo \& Zorn, 2005). En la línea germinal SSEA-1 es expresado en la superficie de los gonocitos y se considera como un marcador de desarrollo temprano de estas células. Este tiende a ser expresado mayormente durante las etapas premigratoria, migratoria y postmigratoria de las CGP, para luego disminuir su expresión (Lacham-Kaplan, 2004).

TEX101 corresponde a un marcador de células germinales identificada tanto en hembras como machos luego del período pregonadal, siendo identificado también en proespermatogonias para desaparecer en las espermatogonias, y después reaparecer en espermatocitos y espermátidas (Takayama et al., 2005). En el ovario su expresión en las células germinales se observa hasta el inicio de la foliculogénesis (Takayama et al.). En este sentido se sugiere que TEX101 tendría un rol en el desarrollo y diferenciación de las células germinales. En el sexo masculino su expresión se inicia al $14 \mathrm{dpc}$, manteniéndose hasta el 4 dpp (día post parto) y luego ocasionalmente hasta el $10 \mathrm{dpp}$ asociado a la aparición de las espermatogonias. En el ovario se inicia al 14 dpc y se mantiene hasta la foliculogénesis aproximadamente al $4 \mathrm{dpp}$ en donde desaparece (Takayama et al.).

La familia de genes piwi en ratón expresa tres proteínas piwi: Mili, Miwi y Miwi2. Los ratones nulos para Miwi no completan la espermatogénesis, deteniéndose en la etapa de espermatocito, similar a lo sucedido en el fenotipo nulo para Mvh. Mili se expresa en las CGP de ratones de ambos sexos, además en espermatogonias y espermatocitos. Además y concordante con esto, existe una asociación entre Mili y Mvh (Kuramochi-Miyagawa et al., 2004).

Tabla I. Expresión de marcadores de CGP durante las distintas etapas del desarrollo, migración y postmigración.

\begin{tabular}{|c|c|c|c|c|c|c|}
\hline Marcador & Pregastrula ción & Premigr ación & Migración & Postmigración & S.F. & S.M. \\
\hline D.E. en dpc & 6,0 & $6,5-7,5$ & $8,5-9,5$ & $10,5-11,5$ & $13,5-17,5$ & $13,5-17,5$ \\
\hline Fragilis1 & $+(6,25)$ & + & + & + & + & + \\
\hline $\mathrm{c}-\mathrm{Kit} / \mathrm{SCF}$ & - & $+(7,5)$ & + & + & $+[13,5]$ & $+[14,5]$ \\
\hline Stella & - & $+(7,5)$ & + & + & $+[13,5]$ & $+[15,5]$ \\
\hline Blimp 1 & $+(6,25)$ & + & + & + & - & - \\
\hline Vasa (MVH) & - & - & - & $+(10,5)$ & + & + \\
\hline DAZL & - & - & - & $+(11,5)$ & + & + \\
\hline SSEA-1 & - & + & + & + & $i^{-/+} ?$ & $i^{-/+?}$ \\
\hline TNAP & - & $+(7,25)$ & + & + & - & - \\
\hline GCNA-1 & - & - & - & $+(10,5)$ & + & + \\
\hline TEX101 & - & - & - & - & $+(14,0)$ & $+(14,0)$ \\
\hline Mili & - & \multicolumn{3}{|c|}{ + en relación a línea germinal masculina } & + & + \\
\hline
\end{tabular}

Abreviaturas: D.E.= Día Embrionario en dpc, $\mathrm{CGP}=$ células germinales primordiales, S.F. = sexo femenino, S.M.= sexo masculino, (inicio de expresión), [fin de expresión], i-/+?= Disminución de expresión sin día específico. 
Tabla II. Función asociada a marcadores de células germinales primordiales (CGP).

\begin{tabular}{ll}
\hline Marcador & Función en CGP \\
\hline Fragilis1 & Migración. \\
c-Kit & Sobrevida, migración y maduración. \\
Stella & Sobrevida y migración en parte, pero no necesario. \\
Blimp1 & Especificación temprana hacia linaje más restringido. \\
Vasa (MVH) & Proliferación y especificación más tardía. \\
DAZL & Desarrollo, diferen ciación y maduración. \\
GCNA-1 & Desconocida. \\
TEX101 & Desarrollo y diferenciación. \\
Mili & Determinación del destino celular germinal. \\
\hline
\end{tabular}

El resumen de la expresión de los distintos marcadores en los diferentes etapas y su función, se ilustras en las Tablas I y II.

\section{Pluripotencialidad y sus marcadores en CG.}

Los criterios de laboratorio comúnmente utilizados para determinar la naturaleza pluripotente de las CGP son (Ledda et al., 2010): a) Diferenciación in vitro en todos los distintos tipos celulares, b) Formación de embriones, c) Formación de teratomas luego del trasplante en la cápsula renal de un ratón con inmunodeficiencia combinada severa y d) Integración en el tejido fetal al ser reintroducidas dentro de un embrión (generación de quimeras).

En los mamíferos todas las células derivadas desde el epiblasto, poseen la capacidad de diferenciarse hacia todos los distintos linajes celulares, es decir son células pluripotenciales (Western, 2009). Dependiendo de sus influencias regionales, vale decir, células epiblásticas anteriores, posteriores, etc., se originarán las distintas células de cada una de las tres hojas embrionarias. Es en el epiblasto post-implantacional, en su parte más proximal, en donde tienen su origen las células germinales primordiales (Chenoweth et al., 2010).

La línea de células germinales, al contrario de la somática, transmite el genoma de generación en generación. Es así como las CGP son las únicas capaces de retener verdaderamente la capacidad de desarrollo pluripotencial luego de la gastrulación, siendo identificada la expresión de diversos marcadores típicos del estado toti y/o pluripotencial (Soto-Suazo \& Zorn).

Este estado de pluripotencialidad es el resultado de una relación entre factores de crecimientos extracelulares y factores de transcripción intracelulares. Respecto a estos últimos existe una triada principal que considera a tres reguladores maestros de transcripción: Oct4, Sox 2 y Nanog.
El primero, Pou5f1/Oct4 (Pou domain class 5 transcription factor 1 or Octamer binding transcription factor 4), corresponde al más conocido y estudiado. Tiene como función codificar un factor de transcripción que posee un dominio POU el que es requerido para mantener la pluripotencialidad en las células madres embrionarias (ES cells) y células preimplantacionales embrionarias (Nichols et al., 1998). La expresión de Oct4 se mantiene durante las etapas de clivaje tempranas, lo cual es restringido específicamente a las células de la masa celular interna, desde donde se origina el epiblasto. Su expresión perdura durante todo el desarrollo de las células germinales primordiales (Saitou et al., 2002). Oct4 se une a una secuencia de consenso octamérica ATGCAAAT, y el análisis de sus datos por inmunoprecipitación de cromatina (ChiP) ha identificado más de 400 supuestos genes diana de Oct4, que también tienden a reclutar a Sox2 y Nanog (Sharov et al., 2008)

Sox 2 es regulada por Oct4, es expresado en las CGP hasta después de poblar las crestas genitales durante la especificación de la vía de la espermatogénesis u ovogénesis, para luego disminuir su expresión (Maldonado-Saldivia et al., 2007).

El tercer regulador de transcripción Nanog, corresponde a un factor tipo homeodominio que se une a la secuencia TAAT y representa el principal objetivo del complejo Oct4/Sox2. Nanog es reactivado en las CG en sus inicios, y su expresión se mantiene en éstas en un patrón similar al observado en Sox2 (Yamaguchi et al., 2005). La regulación de Nanog es un complejo proceso que incluye la regulación de sus promotores mediante Oct4 y Sox2, así como también por FoxD3, P53 y factores de crecimiento como LIF, BMP y Wnt (Pan \& Thomson, 2007).

En conjunto estos tres factores de transcripción Oct4, Sox2 y Nanog regulan una red de genes involucrados en la pluripotencialidad compuesta por aproximadamente 1400 genes diana, siendo éstos subdivididos en 4 grupos principales: factores de transcripción, factores remodeladores de cromatina, reguladores de los ciclos celulares y supresores de señal. La expresión de los tres marcadores va disminuyendo con el desarrollo, siendo casi indetectables al nacimiento y la frecuencia con la que una célula germinal pasa a un estado pluripotencial también decrece gradualmente (Geijsen \& Jones, 2008).

Además de los factores ya mencionados, existen otros marcadores de pluripotencialidad en las CGP, tales como Esg1 (embryonic stem cell specific gene 1 also known as Dppa5), Dppa2 (developmental pluripotency associated gene 2) y 
Dppa4 durante su migración y llegada a las gónadas indiferenciadas (Tanaka et al., 2006; Maldonado-Saldivia et $a l$. .). En el caso de Esg1, éste no sería esencial en células germinales para su especificación y sobrevida (Tanaka et al.). Respecto de Dppa2 y Dppa4, no serían expresados en las células germinales migratorias antes de su entrada en las gónadas (Maldonado-Saldivia et al.). A pesar de esto, mientras que Dppa2 y Dppa4 no son expresados en las CGP tempranas, parecen ser regulados positivamente durante la derivación de las CGP a células germinales embrionarias (EG), en donde ya son detectados. En este sentido Dppa2 y Dppa4 no parecen ser necesarios para la pluripotencialidad de las CGP, pero si serían necesarios para la formación de EG (Western).

Técnicas de estudio de las células germinales primordiales.

Aislamiento de las CGP durante la fase premigratoria: Hembras de la especie murina son sacrificados entre los días 7 y 8 de gestación y los embriones son disecados y extraídos del útero. Luego, mediante el uso de anticuerpos monoclonales capaces de unirse a las moléculas de superficie de las CGP, se identifica al grupo ubicado a nivel próximo al epiblasto en cercanía del ectodermo extra embrionario comprendido entre los días 6-6,5 dpc mediante la tinción para detectar FA (fosfatasa alcalina), mientras que al grupo ubicado nivel del mesoderma extraembrionario entre los días y 7,0-7,5 dpc mediante tinción para FA Y E-Cadherina en su superficie (Soto-Suazo \& Zorn).

Aislamiento de las CGP durante la fase de migración y postmigración: Hembras de la especie murina son sacrificados entre los días 9 y 13,5 de gestación y los embriones son disecados y extraídos del útero. Las crestas genitales son disecadas de los embriones y el mesenterio dorsal es removido (Rojas et al., 2001). Los tejidos recolectados son lavados con PBS e incubados en solución de tripsina al 0,04 \% y EDTA al $0,25 \%$ durante $5 \mathrm{~min}$ a temperatura ambiental (Kakegawa $e t$ al., 2008). Para la obtención de las CGP durante la fase postmigratoria de los embriones murinos entre los días 12,5 a 13,5 dpc, se realiza una disgregación mecánica, seguido del método gradiente discontinuo de Percoll para aumentar el nivel de purificación de estas células a un 80-90 \% (De Felici, 2000).

Para optimizar la caracterización celular, se utiliza un estudio morfológico asociado a la utilización de anticuerpos monoclonales capaces de unirse a las moléculas de superficie de las CGP (De Felici). Es así como entre los días 10 y 11 ubicadas las CGP a nivel del mesenterio dorsal, con morfología celular irregular asociada a proyecciones celulares tipo pseudópodos, presentan marcadores de superficie para FA, SSEA-1, c-Kit, integrinas 6, 5, 3, 1, P-y E-Cadherinas y PECAM-1. Mientras que las CGP que ya colonizaron la cresta genital adquieren una morfología redondeada (Soto-Suazo \& Zorn) presentando heterogeneidad en los marcadores de superficie c-Kit e integrina alfa 6. Estos cambios pueden reflejar asincronía en la diferenciación celular y del estado de supervivencia. Es así como las CGP que no expresan c-kit ni integrina alfa 6, presentan mayor nivel de apoptosis que su contraparte (Morita-Fujimura et al.).

Cultivo de las CGP: El uso de una capa alimentadora para las CGP, ha permitido mejorar gradualmente el cultivo de estas células estableciendo condiciones de supervivencia y de proliferación (De Felici). Otros métodos que han aportado, son los sistemas de co-cultivo de las CGP con células somáticas gonadales, mediante el aporte de factores de supervivencia o de proliferación (De Felici). Dentro de los factores de crecimiento tenemos el LIF y SCF. Este último es producido por las células somáticas vecinas durante la fase migratoria y postmigratoria, el cual se une al receptor tirosina quinasa c-kit de las CGP. Ambos aumentan la supervivencia de las CGP al disminuir la apoptosis celular, por reducción de la expresión de la proteína pro apoptótica Bax. Otros factores tales como Forskolin (FRSK) y el agonista AMPc, estimulan la proliferación de las CGP. Dentro de los factores que estimulan la vía AMPc se encuentran la FSH, prostaglandinas, $\mathrm{ACTH}$, calcitonina y T3. Por último el ácido retinoico actúa en forma sinérgica con FRSK para estimular la proliferación de las CGP (De Felici).

\section{Mecanismos que regulan el desarrollo de las CGP}

Formación de células germinales primordiales: La señalización mediante BMP es esencial para la formación de las CGP (de Sousa Lopes et al., 2004). La activación de la cascada de señalización a través de BMP4 producida en el ectodermo extraembrionario, es necesario para la generación de células germinales primordiales, mientras que otros BMPs tales como BMP8b (producido por el ectodermo extraembrionario) y BMP2 (producido por el endodermo visceral), han demostrado su importancia en el establecimiento del número normal de estas células. En esta misma etapa, Fragilis es detectado a nivel del epiblasto proximal entre los días 6,25 y 6,5 dpc (de Sousa Lopes et al., 2004).

Los BMPs pertenecen a la superfamilia de TGF. A nivel de superficie celular, el dímero de BMP se une al receptor tipo I (activin receptor-like kinase; ALK2, ALK3, o ALK6) y al receptor tipo II (BMPR-II, ActR-IIA, o ActRIIB) para la formación de complejos heteroméricos. El receptor de BMP tipo II fosforila al receptor de BMP tipo I, permitiendo a su vez la fosforilación de Smads (Smad1, Smad5, o Smad8). La activación de estos Smads, permite la traslocación de Smad4 del citoplasma al núcleo para la regulación de la transcripción génica. 
Se ha demostrado que tanto la activación de Smad1 como de Smad5 son importantes para la inducción de las CGP (de Sousa Lopes et al., 2004).

La producción de BMP4 a nivel del ectodermo extraembrionario, y su señalización a través del receptor tipo I ALK2 a nivel del endodermo visceral entre los días 5,5 y 6,0 dpc, es necesario para la formación de las CGP a partir del epiblasto (de Sousa Lopes et al., 2004) (Fig. 1).

Migración: En cuanto a la proliferación de las CGP durante la fase migratoria, estas son estimuladas de forma paracrina por las células vecinas mediante FGF-4, FGF-8 y FGF-17. A la vez, la formación y proliferación de estas células es dependiente de BMPs 2, 4 y 8b (Dudley et al. 2010). Las CGP que no migraron en forma adecuada para llegar a la cresta genital, ubicándose de manera ectópica, mueren rápidamente por apoptosis mediante la expresión de la proteína pro apoptótica Bax (Eckert et al., 2008).

En cuanto a la migración de las CGP, la actividad del quimioatractante del ligando SCF, ha evidenciado la capacidad de reorganizar las fibras de actina de las CGP para permitir su migración. La unión de este ligando al receptor c-Kit de las CGP, permite un aumento de la autofosforilación de este receptor, seguido de la fosforilación en serina treonina de la quinasa AKT a través de la acción de PI3K. Otros factores involucrados en la migración de la CGP secretados por parte de las células somáticas vecinas, co- rresponden al factor 1 derivado del estroma (SDF1) y su receptor CXCR4 y al factor TGFb1 y su receptor ALK5 (Farini et al.) (Fig. 2A) .

Postmigración: Al llegar las CGP al esbozo gonádico, éstas comienzan a secretar FGF-4 y FGF-8 para estimular su proliferación de manera autocrina (Kawase et al., 2004). Por otra parte el SCF modula la respuesta de FGF, regulando por ende, la proliferación de las células primordiales germinales. Este factor actúa promoviendo la proliferación actuando sinérgicamente junto a FGF en ausencia del receptor de membrana de unión a SCF, mientras que actúa inhibiendo la acción del FGF cuando se encuentra este último receptor de membrana presente (Kawase et al., 2004).

BMP7 es expresado en las gónadas y es requerido también para la proliferación de las CGP. La pérdida de señalización de BMP lleva a una disminución en el número de células germinales primordiales y alteración de la migración. Esto ocurre indirectamente por aumento de la muerte de las células somáticas y del mesénquima mesonéfrico. Estos hallazgos se correlacionan con una reducción del nivel del marcador mesonéfrico Pax2, asícomo también de los genes expresados en el epitelio celómico SCF y Sdf1a, involucrados en la quimioatracción de células germinales primordiales. Por lo tanto la señalización BMP promueve la supervivencia de las células mesonéfricas de la cresta genital, permitiendo un correcto desarrollo del epitelio celómico que actúa sobre las CGP (Dudley et al.) (Fig. 2B).

\section{Formación de las CGP: (6.0-7.5 dpc)}

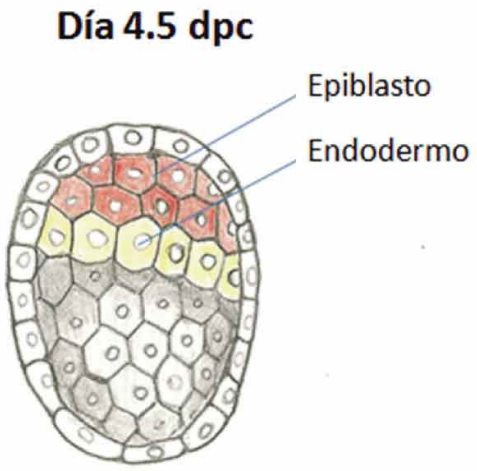

\section{Día $6.0-6.5$ dpc}

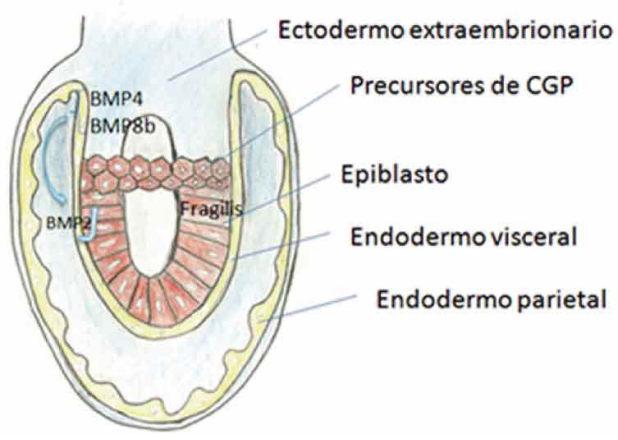

Fig. 1. Formación de las células germinales primordiales (CGP). Se ilustra la etapa de blastocisto entre los días 4,5 y 6,0 dpc, con los grupos de células correspondientes al epiblasto, que darán origen a las CGP y el endodermo primitivo. En una etapa más avanzada $(6,0-6,5 \mathrm{dpc})$, el ectodermo extraembrionario estimula el endodermo visceral a través de los factores BMP4 y BMP8 para que luego el endodermo visceral secrete BMP2 para dar lugar en conjunto a la formación de las CGP a partir del epiblasto. En esta etapa se puede detectar el factor fragilis a nivel del epiblasto proximal. 


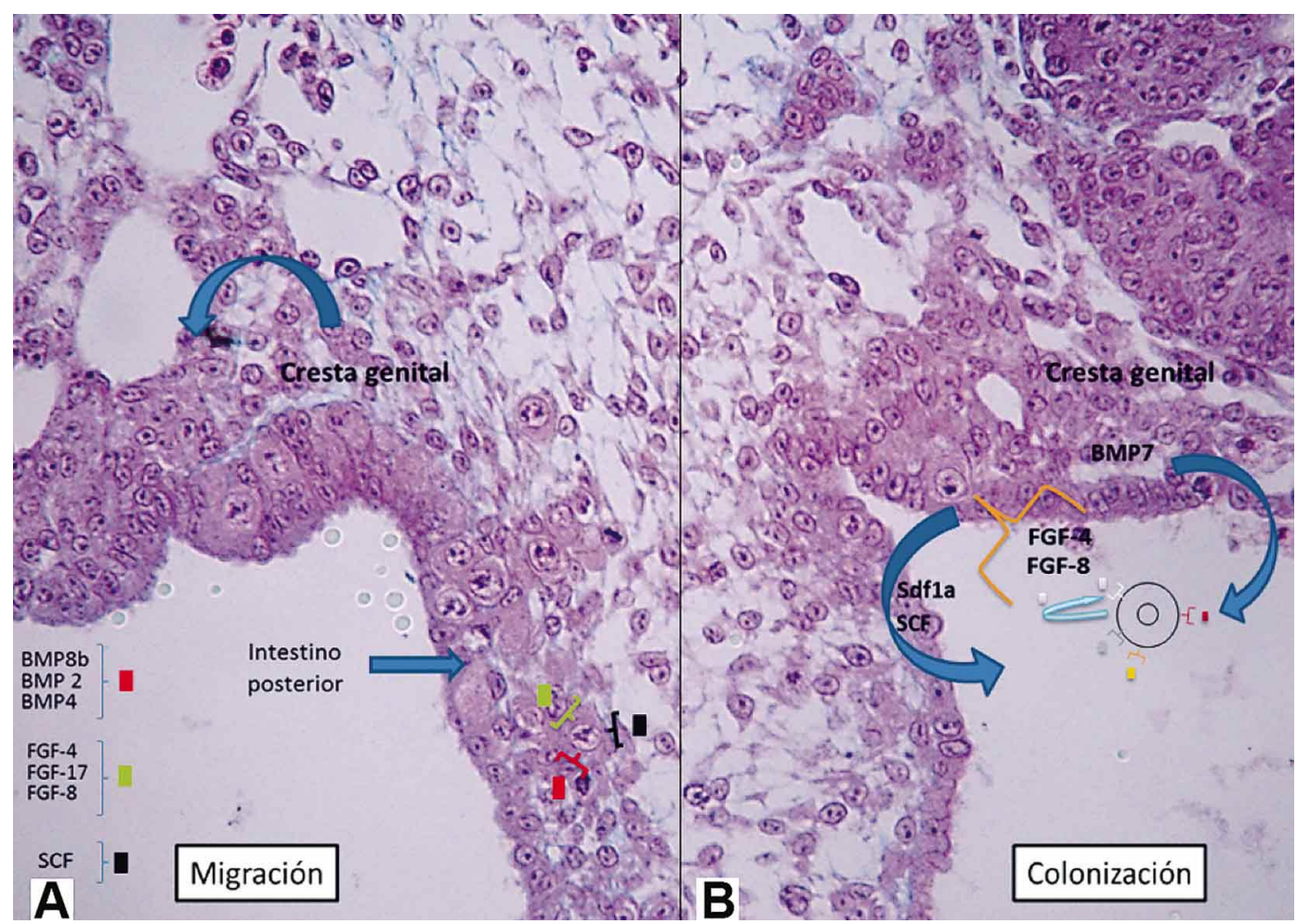

Fig. 2. Migración y colonización de las células germinales primordiales (CGP). A) Etapa de migración de las CPG entre los días 7,5-10,5dpc. Se ilustra la migración de las CGP a lo largo del intestino primitivo en dirección a la cresta genital. Estas son estimuladas de forma paracrina por las células vecinas mediante FGF4, FGF8 , FGF17, BMP 2,4 y 8f para su formación y proliferación. Por otra parte el ligando SCF actúa facilitando la migración. (Fotografía original de M. Rojas. Programa de Anatomía y Biología del Desarrollo. Universidad de Chile). B) A nivel del epitelio celómico es secretado SCF y Sdf1a para la quimioatracción de las CGP. Estas células comienzan a proliferar por medio de una estimulación autocrina por FGF-4 y FGF-8 y de manera paracrina por BMP7 secretado por las gónadas. Abreviatura: CGP = célula germinal primordial (Fotografía original de M. Rojas. Programa de Anatomía y Biología del Desarrollo. Universidad de Chile).

\section{AGRADECIMIENTOS}

Especial agradecimiento a la Doctora Mariana Rojas R., por su constante apoyo, ayuda y participación para la realización de este artículo.

STEVENSON, A.; OBAÍD, M.; ROMINA, R. \& VIGNEAUX, L. Characterization and marking of primordial germ cells. Int. J. Morphol., 34(2):628-636, 2016.

SUMMARY: Primordial germ cells (PGC) are the precursors of oocytes and spermatocytes. They are characterized by being the only ones capable of accurately retaining pluripotent developmental ability after gastrulation. These cells come from the epiblast, they differ from somatic cells by signals from the extra-embryonic ectoderm and visceral endoderm, starting from day 6.0 to $7.5 \mathrm{dpc}$ in murine species. Then migrate through the primitive gut and dorsal mesentery to reach genital ridges around
$10.5 \mathrm{dpc}$. The primordial germ cells have a varied morphology and gene expression therefore have different markers according to the stage where they are. Among the most studied and characterized markers are Fragilis, c-Kit, Stella, DAZ, Vasa, GCNA1, Blimp1 and SSEA-1.

KEY WORDS: Primordial germ cells; Markers; Pluripotential.

\section{REFERENCIAS BIBLIOGRÁFICAS}

Chenoweth, J. G.; McKay, R. D. \& Tesar, P. J. Epiblast stem cells contribute new insight into pluripotency and gastrulation. Dev. Growth Differ., 52(3):293-301, 2010.

De Felici, M. Regulation of primordial germ cell development in the mouse. Int. J. Dev. Biol., 44(6):575-80, 2000. 
de Sousa Lopes, S. M.; Hayashi, K. \& Surani, M. A. Proximal visceral endoderm and extraembryonic ectoderm regulate the formation of primordial germ cell precursors. BMC Dev. Biol., 7:140, 2007.

de Sousa Lopes, S. M.; Roelen, B. A.; Monteiro, R. M.; Emmens, R.; Lin, H. Y.; Li, E.; Lawson, K. A. \& Mummery, C. L. BMP signaling mediated by ALK2 in the visceral endoderm is necessary for the generation of primordial germ cells in the mouse embryo. Genes Dev., 18(15):1838-49, 2004.

Dudley, B.; Palumbo, C.; Nalepka, J. \& Molyneaux, K. BMP signaling controls formation of a primordial germ cell niche within the early genital ridges. Dev. Biol., 343(1-2):84-93, 2010.

Eckert, D.; Biermann, K.; Nettersheim, D.; Gillis, A. J.; Steger, K.; Jäck, H. M.; Müller, A. M.; Looijenga, L. H. \& Schorle, H. Expression of BLIMP1/PRMT5 and concurrent histone $\mathrm{H} 2 \mathrm{~A} / \mathrm{H} 4$ arginine 3 dimethylation in fetal germ cells, CIS/ IGCNU and germ cell tumors. BMC. Dev. Biol., 8:106, 2008.

Enders, G. C. \& May, J. J. 2nd. Developmentally regulated expression of a mouse germ cell nuclear antigen examined from embryonic day 11 to adult in male and female mice. Dev. Biol., 163(2):331-40, 1994.

Farini, D.; La Sala, G.; Tedesco, M. \& De Felici, M. Chemoattractant action and molecular signaling pathways of Kit ligand on mouse primordial germ cells. Dev. Biol., 306(2):572-83, 2007.

Geijsen, N. \& Jones, D. L. Seminal discoveries in regenerative medicine: contributions of the male germ line to understanding pluripotency. Hum. Mol. Genet., 17(R1):R16-22, 2008.

Hopf, C.; Viebahn, C. \& Püschel, B. BMP signals and the transcriptional repressor BLIMP1 during germline segregation in the mammalian embryo. Dev. Genes Evol., 221(4):209-23, 2011.

Kakegawa, R.; Teramura, T.; Takehara, T.; Anzai, M.; Mitani, T.; Matsumoto, K.; Saeki, K.; Sagawa, N.; Fukuda, K. \& Hosoi, Y. Isolation and culture of rabbit primordial germ cells. $J$. Reprod. Dev., 54(5):352-7, 2008.

Kawase, E.; Hashimoto, K. \& Pedersen, R. A. Autocrine and paracrine mechanisms regulating primordial germ cell proliferation. Mol. Reprod. Dev., 68(1):5-16, 2004.

Kuramochi-Miyagawa, S.; Kimura, T.; Ijiri, T. W.; Isobe, T.; Asada, N.; Fujita, Y.; Ikawa, M.; Iwai, N.; Okabe, M.; Deng, W.; Lin, H.; Matsuda, Y. \& Nakano, T. Mili, a mammalian member of piwi family gene, is essential for spermatogenesis. Development, 131(4):839-49, 2004.

Kurimoto, K.; Yabuta, Y.; Ohinata, Y.; Shigeta, M.; Yamanaka, K. \& Saitou, M. Complex genome-wide transcription dynamics orchestrated by Blimp1 for the specification of the germ cell lineage in mice. Genes Dev., 22(12):1617-35, 2008.
Lacham-Kaplan, O. In vivo and in vitro differentiation of male germ cells in the mouse. Reproduction, 128(2):147-52, 2004.

Lange, U. C.; Saitou, M.; Western, P. S.; Barton, S. C. \& Surani, M. A. The fragilis interferon-inducible gene family of transmembrane proteins is associated with germ cell specification in mice. BMC Dev. Biol., 3:1, 2003.

Ledda, S.; Bogliolo, L.; Bebbere, D.; Ariu, F. \& Pirino, S. Characterization, isolation and culture of primordial germ cells in domestic animals: recent progress and insights from the ovine species. Theriogenology, 74(4):534-43, 2010.

Maldonado-Saldivia, J.; van den Bergen, J.; Krouskos, M.; Gilchrist, M.; Lee, C.; Li, R.; Sinclair, A. H.; Surani, M. A. \& Western, P. S. Dppa2 and Dppa4 are closely linked SAP motif genes restricted to pluripotent cells and the germ line. Stem Cells, 25(1):19-28, 2007.

McLaren, A. Primordial germ cells in the mouse. Dev. Biol., 262(1):1-15, 2003.

Morita-Fujimura, Y.; Tokitake, Y. \& Matsui, Y. Heterogeneity of mouse primordial germ cells reflecting the distinct status of their differentiation, proliferation and apoptosis can be classified by the expression of cell surface proteins integrin a6 and c-Kit. Develop. Growth Differ., 51(6):567$83,2009$.

Nichols, J.; Zevnik, B.; Anastassiadis, K.; Niwa, H.; KleweNebenius, D.; Chambers, I.; Schöler, H. \& Smith, A. Formation of pluripotent stem cells in the mammalian embryo depends on the POU transcription factor Oct4. Cell, 95(3):379-91, 1998.

Ohinata, Y.; Payer, B.; O’Carroll, D.; Ancelin, K.; Ono, Y.; Sano, M.; Barton, S. C.; Obukhanych, T.; Nussenzweig, M.; Tarakhovsky, A.; Saitou, M. \& Surani, M. A. Blimp1 is a critical determinant of the germ cell lineage in mice. Nature, 436(7048):207-13, 2005.

Pan, G. \& Thomson, J. A. Nanog and transcriptional networks in embryonic stem cell pluripotency. Cell Res., 17(1):42-9, 2007.

Payer, B.; Saitou, M.; Barton, S. C.; Thresher, R.; Dixon, J. P.; Zahn, D.; Colledge, W. H.; Carlton, M. B.; Nakano, T. \& Surani, M. A. Stella is a maternal effect gene required for normal early development in mice. Curr. Biol., 13(23):21107, 2003.

Rojas, M.; Vignon, X.; Montenegro, M. A.; del Sol, M.; BustosObregón, E. \& Fléchon, J. Caracterización, aislamiento y cultivo de células germinales primordiales de conejo. Rev. Chil. Anat., 19(2):213-20, 2001.

Saiti, D. \& Lacham-Kaplan, O. Mouse Germ Cell Development in-vivo and in-vitro. Biomark. Insights, 2:241-52, 2007. 
Saitou, M.; Barton, S. C. \& Surani, M. A. A molecular programme for the specification of germ cell fate in mice. Nature, 418(6895):293-300, 2002.

Saitou, M.; Payer, B.; Lange, U. C.; Erhardt, S.; Barton, S. C. \& Surani, M. A. Specification of germ cell fate in mice. Philos. Trans. R. Soc. Lond. B. Biol. Sci., 358(1436):1363-70. 2003.

Sato, M.; Kimura, T.; Kurokawa, K.; Fujita, Y.; Abe, K.; Masuhara, M.; Yasunaga, T.; Ryo, A.; Yamamoto, M. \& Nakano, T. Identification of PGC7, a new gene expressed specifically in preimplantation embryos and germ cells. Mech. Dev., 113(1):91-4, 2002.

Sette, C.; Dolci, S.; Geremia, R. \& Rossi, P. The role of stem cell factor and of alternative c-kit gene products in the establishment, maintenance and function of germ cells. Int. J. Dev. Biol., 44(6):599-608, 2000.

Sharov, A. A.; Masui, S.; Sharova, L. V.; Piao, Y.; Aiba, K. Matoba, R.; Xin, L.; Niwa, H. \& Ko, M. S. Identification of Pou5f1, Sox2, and Nanog downstream target genes with statistical confidence by applying a novel algorithm to time course microarray and genome-wide chromatin immunoprecipitation data. BMC Genomics, 9:269, 2008.

Soto-Suazo, M. \& Zorn, T. M. Primordial germ cells migration: morphological and molecular aspects. Anim. Reprod., 2(3):14760, 2005.

Takayama, T.; Mishima, T.; Mori, M.; Jin, H.; Tsukamoto, H.; Takahashi, K.; Takizawa, T.; Kinoshita, K.; Suzuki, M.; Sato, I.; Matsubara, S.; Araki, Y. \& Takizawa, T. Sexually dimorphic expression of the novel germ cell antigen TEX101 during mouse gonad development. Biol. Reprod., 72(6):1315-23, 2005.

Tanaka, S. S. \& Matsui, Y. Developmentally regulated expression of $\mathrm{mil}^{-1}$ and $\mathrm{mil}^{-2}$, mouse interferon-induced transmembrane protein like genes, during formation and differentiation of primordial germ cells. Mech. Dev., 119 (Suppl. 1):S261-7, 2002.

Tanaka, T. S.; Lopez de Silanes, I.; Sharova, L. V.; Akutsu, H.; Yoshikawa, T.; Amano, H.; Yamanaka, S.; Gorospe, M. \& Ko, M. S. Esg1, expressed exclusively in preimplantation embryos, germline, and embryonic stem cells, is a putative RNA-binding protein with broad RNA targets. Dev. Growth Differ., 48(6):381-90, 2006.

Toyooka, Y.; Tsunekawa, N.; Takahashi, Y.; Matsui, Y.; Satoh, M. \& Noce, T. Expression and intracellular localization of mouse Vasa-homologue protein during germ cell development. Mech. Dev., 93(1-2):139-49, 2000.

Western, P. Foetal germ cells: striking the balance between pluripotency and differentiation. Int. J. Dev. Biol., 53(2-3):393409, 2009.
Yamaguchi, S.; Kimura, H.; Tada, M.; Nakatsuji, N. \& Tada, T. Nanog expression in mouse germ cell development. Gene Expr. Patterns, 5(5):639-46, 2005.

Yen, P. H. Putative biological functions of the DAZ family. Int. J. Androl., 27(3):125-9, 2004.

\author{
Dirección para Correspondencia: \\ Miguel Obaíd \\ Médico Cirujano \\ Magister en Ciencias Médicas y Biológicas \\ Mención Morfología \\ Laboratorio de Embriología Comparada \\ Programa de Anatomía y Biología del Desarrollo, ICBM \\ Facultad de Medicina \\ Universidad de Chile \\ Santiago \\ CHILE
}

Email: miguel.obaid.g@gmail.com

Recibido: 27-05-2015

Aceptado: 29-02-2016 